\title{
Gentamicin Combined With Hypoionic Shock Rapidly Eradicates Aquaculture Bacteria in vitro and in vivo
}

\begin{abstract}
Yuanyuan Gao ${ }^{1,2 *}$, Zhongyu Chen ${ }^{1 \dagger}$, Wei Yao ${ }^{1}$, Daliang Li ${ }^{3,4}$ and Xinmiao Fu' ${ }^{1,2 *}$
${ }^{1}$ Provincial University Key Laboratory of Cellular Stress Response and Metabolic Regulation, Key Laboratory of Optoelectronic Science and Technology for Medicine of Ministry of Education, College of Life Sciences, Fujian Normal University, Fuzhou, China, ${ }^{2}$ Engineering Research Center of Industrial Microbiology of Ministry of Education, Fujian Normal University, Fuzhou, China, ${ }^{3}$ Fujian Key Laboratory of Innate Immune Biology, Biomedical Research Center of South China, Fuzhou, China, ${ }^{4}$ College of Life Science, Fujian Normal University, Fuzhou, China
\end{abstract}

\section{OPEN ACCESS}

Edited by:

Bo Peng,

Sun Yat-sen University, China

Reviewed by:

Hetron Mweemba Munang'andu, Norwegian University of Life Sciences,

Norway

Xiangmin Lin,

Fujian Agriculture and Forestry University, China

*Correspondence: Yuanyuan Gao gaoy@fjnu.edu.cn

Xinmiao Fu

xmfu@fjnu.edu.cn

tThese authors have contributed equally to this work

Specialty section: This article was submitted to Antimicrobials, Resistance and Chemotherapy,

a section of the journal

Frontiers in Microbiology

Received: 15 December 2020

Accepted: 01 March 2021

Published: 06 April 2021

Citation:

Gao Y, Chen Z, Yao W, Li D and Fu X (2021) Gentamicin Combined

With Hypoionic Shock Rapidly Eradicates Aquaculture Bacteria in

vitro and in vivo.

Front. Microbiol. 12:641846. doi: 10.3389/fmicb.2021.641846
Bacterial pathogens are a major cause of infectious diseases in aquatic animals. The abuse of antibiotics in the aquatic industry has led to the proliferation of antibiotic resistance. It is therefore essential to develop more effective and safer strategies to increase the efficacy and extend the life span of the antibiotics used in aquaculture. In this study, we show that six aquaculture bacterial pathogens (i.e., Aeromonas hydrophila, Vibrio alginolyticus, Edwardsiella tarda, Streptococcus iniae, Vibrio harveyi, and Vibrio fluvialis) in the stationary phase can be rapidly killed after immersion in gentamicin- or neomycin-containing, ion-free solutions for a few minutes. Such hypoionic shock treatment enhances the bacterial uptake of gentamicin in an ATP-dependent manner. Importantly, we demonstrate, as a proof of concept, that gentamicin under hypoionic shock conditions can effectively kill $A$. hydrophila in vivo in a skin infection model of zebrafish (Danio rerio), completely curing the infected fish. Given that pathogenic bacteria generally adhere to the skin surface and gills of aquatic animals, our strategy is of potential significance for bacterial infection control, especially for small-scale economic fish farming and ornamental fish farming. Further, the combined treatment can be completed within 5 min with a relatively small volume of solution, thus minimizing the amount of residual antibiotics in both animals and the environment.

Keywords: aquaculture bacteria, persister, antibiotic tolerance, aminoglycoside, gentamicin, neomycin, hypoionic shock, zebrafish

\section{INTRODUCTION}

Aquaculture is the fastest-growing animal food industry at present and provides human society with one of the most sustainable forms of edible protein and nutrient production, making it a fundamental part of future food production (Froehlich et al., 2018). Similar to other animal production sectors, fish production relies on intensive and semi-intensive cultivations, which result in increased disease outbreaks (Little et al., 2016; Kotob et al., 2017). Fish diseases are often caused by bacteria, viruses, fungi, parasites, or a combination of these pathogens, with bacterial pathogens 
being the most common etiology (Dhar et al., 2014; Lafferty et al., 2015). Given that bacteria can survive well in aquatic environments independent of a host, bacterial diseases have become major impediments to aquaculture (Haenen et al., 2013). Various effective vaccines have been developed against many fish bacterial pathogens. Nevertheless, some infectious bacterial diseases that cannot be controlled using conventional inactivated vaccines are threatening aquaculture (Tafalla et al., 2013). In addition, attenuated bacterial vaccines can potentially revert to a pathogenic form, which poses a tremendous risk to the whole environment (Matsuura et al., 2019). Furthermore, some bacterial pathogens are difficult to culture or completely unculturable, making them unsuitable for vaccine development (Takano et al., 2016).

Antibiotics are widely used to prevent and control bacterial diseases in aquaculture (Cabello et al., 2016; Santos and Ramos, 2018). Nevertheless, long-term antibiotic usage, particular overuse and misuse, has led to the emergence and proliferation of antibiotic resistance (Baym et al., 2016; Du et al., 2019). Improving the efficacy of antibiotics is a promising strategy for extending the life span of current antibiotic drugs (Levy and Marshall, 2004; Nambiar et al., 2014). Previously, we found that treatment in non-electrolyte (e.g., glycerol) solutions or in ultrapure water exhibits a potentiation effect on the killing of bacteria by aminoglycosides, while treatment in strong electrolyte (e.g., $\mathrm{NaCl}$ ) solutions barely exhibits any potentiation effects (Jiafeng et al., 2015). In particular, stationary-phase Escherichia coli cells can be killed after treatment in aminoglycosidecontaining ultrapure water for only 1-2 min (Jiafeng et al., 2015). It should be noted that bacteria enter a non-growth state defined as a stationary phase when nutrients are insufficient in their living surroundings (Navarro Llorens et al., 2010), and stationary-phase bacteria are much more resistant than exponential-phase cells to destruction by antibiotics (Levin and Rozen, 2006; McCall et al., 2019). Furthermore, we showed that such hypoionic shock (i.e., the absence of ions) could dramatically potentiate the killing of nutrient shift- or starvation-induced E. coli persister cells by aminoglycosides in 3 min (Chen et al., 2019).

Here, we investigated whether this unique approach can kill aquaculture bacterial pathogens, given that bacterial pathogens usually infect fish by attaching to their skin surface, gills, and gut lining, which are always in intimate contact with the surrounding water (Benhamed et al., 2014). We show that six aquaculture bacterial pathogens (i.e., Aeromonas hydrophila, Vibrio alginolyticus, Edwardsiella tarda, Streptococcus iniae, Vibrio harveyi, and Vibrio fluvialis) in the stationary phase are killed rapidly in vitro by gentamicin and neomycin under hypoionic shock conditions. Importantly, we demonstrate the in vivo efficacy of the new approach against $A$. hydrophila infections in a zebrafish model.

\section{MATERIALS AND METHODS}

\section{Strains, Media, and Reagents}

The aquatic bacterial strains used in this study consisted of five Gram-negative bacteria (i.e., Aeromonas hydrophila,
Vibrio alginolyticus, Edwardsiella tarda, Vibrio harveyi, and Vibrio fluvialis) and one Gram-positive strain (i.e., Streptococcus iniae). The sources of all aquatic bacterial strains and their relevant characteristics are listed in Supplementary Table S1. Bacteria were cultured in Lysogeny broth (LB) medium at $37^{\circ} \mathrm{C}$ ( $V$. alginolyticus, E. tarda, V. harveyi, and $V$. fluvialis) or $30^{\circ} \mathrm{C}$ (A. hydrophila and S. iniae) in a shaker (220 rpm). The antibiotics used in this study were gentamicin and neomycin. Other chemicals used included carbonyl cyanide $m$-chlorophenyl hydrazone (CCCP) and its analog carbonyl cyanide-trifluoromethoxyphenyl hydrazone (FCCP), as well as eugenol (an anesthetic for zebrafish). The information for the antibiotics and chemicals used in the study is presented in Supplementary Table S2. All chemical reagents were of analytical purity.

\section{Antibiotic Tolerance Test for Six Aquatic Bacterial Cells in Stationary Phase}

In brief, the aquatic bacterial strains from frozen stock listed in Supplementary Table $\mathbf{S 1}$ were seeded in LB medium at a ratio of $1: 1,000$ and cultured at $37^{\circ} \mathrm{C}$ ( V. alginolyticus, E. tarda, V. harveyi, and $V$. fluvialis) or $30^{\circ} \mathrm{C}$ (A. hydrophila and S. iniae) in a shaker $(220 \mathrm{rpm})$ for $24 \mathrm{~h}$ to prepare stationary-phase cells, as previously described (Yao et al., 2016; Chen et al., 2019). Each antibiotic was added to the cultured cells at varying concentrations (refer to Supplementary Table S2), and the mixture was further agitated for $5 \mathrm{~min}$ or $3 \mathrm{~h}$. Hundred microliters of the treated cells was washed twice using phosphate-buffered saline (PBS; $0.27 \mathrm{~g} / \mathrm{L}$ of $\mathrm{KH}_{2} \mathrm{PO}_{4}, 1.42 \mathrm{~g} / \mathrm{L}$ of $\mathrm{Na}_{2} \mathrm{HPO}_{4}, 8 \mathrm{~g} / \mathrm{L}$ of $\mathrm{NaCl}$, and $0.2 \mathrm{~g} / \mathrm{L}$ of $\mathrm{KCl}, \mathrm{pH}=7.4)$ with centrifugation $(13,000 \mathrm{~g}, 30 \mathrm{~s})$ and spot-plated onto LB agar dishes at a 10 -fold serial dilution in PBS. After incubation at $37^{\circ} \mathrm{C}$ for at least $12 \mathrm{~h}$, the colonyforming units (CFU) on the dishes were counted after taking a picture of each dish.

\section{Eradication of Aquatic Bacteria by Aminoglycosides Under Hypoionic Shock Conditions}

Treatment with aminoglycosides combined with hypoionic shock was performed as previously described (Jiafeng et al., 2015; Chen et al., 2019). In brief, $100 \mu l$ of stationary-phase cells was centrifuged $(12,000 \mathrm{~g}, 1 \mathrm{~min})$ in an Eppendorf tube, and the medium was completely removed. Cell pellets were resuspended in ultrapure water (i.e., without the presence of ions; $0.9 \% \mathrm{NaCl}$ solution was used as the negative control) containing gentamicin or neomycin at the concentrations listed in Supplementary Table S2. Ultrapure water was prepared by Milli-Q ${ }^{\circledR}$ Advantage A10 (Millipore). The cell suspension was kept at room temperature (i.e., $25^{\circ} \mathrm{C}$ ) for $5 \mathrm{~min}$, and the cells were washed twice with PBS before spot-plating on LB agar dishes for cell survival assays as described above. Similarly, the effect of ATP was evaluated by agitating the cell culture in the presence of $20 \mu \mathrm{M}$ of protonophore CCCP or FCCP for $1 \mathrm{~h}$ before the combined treatment. 


\section{Intracellular ATP Level Assay}

A luciferase-based kit (BacTiter-Glo ${ }^{\mathrm{TM}}$, Promega, G8231) was used to measure ATP levels according to the manufacturer's instructions. Briefly, stationary-phase cells, with or without $20 \mu \mathrm{M}$ of protonophore CCCP or FCCP pretreatment for $1 \mathrm{~h}$, were quickly mixed with the working solution at equal volumes and then transferred to a 96-well plate before light recording on a FLUOstar Omega Microplate Reader using a Luminometer.

\section{Assay for the Uptake of Fluorescent-Labeled Gentamicin}

A fluorescent probe $\left(\operatorname{Ex}_{580} \mathrm{~nm}, \mathrm{Em}_{600-700 \mathrm{~nm}}\right)$ was attached to gentamicin as we recently reported (Wu et al., 2020). After salts were removed through dialysis, the fluorescent-labeled gentamicin was dissolved in ultrapure water at $100 \mu \mathrm{g} / \mathrm{ml}$ for the treatment of $A$. hydrophila or $V$. alginolyticus cells as described above. The cells were then washed twice with PBS and resuspended in $500 \mu \mathrm{l}$ of cell wall-digestion buffer $(30 \mathrm{mM}$ of Tris-HCl, $\mathrm{pH} 8.0,1 \mathrm{mM}$ of EDTA, $1 \mathrm{mg} / \mathrm{ml}$ of lysozyme) for further incubation at room temperature for $5 \mathrm{~h}$. The cells were subjected to three cycles of freezing treatment at $-80^{\circ} \mathrm{C}$, followed by thermal denaturation at $90^{\circ} \mathrm{C}$ for $10 \mathrm{~min}$ (note: we confirmed that gentamicin had high thermal stability; Chen et al., 2019), and then centrifuged to remove the cell debris and denatured proteins. Afterward, an equal volume of supernatant containing fluorescent-labeled gentamicin was placed in a quartz cuvette, and the fluorescence intensity in the supernatant was determined with a fluorescence spectrometer (Spectrofluorometer FS5, EDINBURGH). In addition, the amount of fluorescent-labeled gentamicin uptaken by CCCP or FCCP-pretreated cells was measured. A standard curve was prepared by directly adding fluorescent-labeled gentamicin at different concentrations $(0,25$, 50 , and $100 \mu \mathrm{g} / \mathrm{ml}$ ) to persister cells suspended in cell wall digestion buffer. All procedures described above were performed under dim lighting to prevent fluorescence quenching.

\section{Animal Experiments}

Zebrafish were purchased from Fuzhou aquarium market and acclimated for 2 weeks before infection. The zebrafish were handled according to the procedures defined by the Animal Ethical and Welfare Committee of Fujian Normal University (approval no. IACUC 20190006, Fuzhou, China). The zebrafish were anesthetized after being immersed in $45 \mathrm{mg} / \mathrm{L}$ of eugenol for about 8 min (Sánchez-Vázquez et al., 2011). After anesthesia, the fish were lightly scraped along the lateral surface behind the pectoral fins with a sterile scalpel to remove several scales (Neely et al., 2002; Zhang et al., 2016). When the scraped fish recovered from anesthesia, they were infected by swimming in water containing $5.0 \times 10^{7} \mathrm{CFU} / \mathrm{ml}$ of $A$. hydrophila at $30^{\circ} \mathrm{C}$ for $3 \mathrm{~h}$. Zebrafish infected by A. hydrophila were rinsed with deionized water for a few seconds and then were randomly divided into three groups (A: mock group without treatment; B: treated with gentamicin-containing ultrapure water; and C: treated with gentamicin-containing $0.9 \% \mathrm{NaCl}$ solution). The concentration of gentamicin in animal experiments is $25 \mu \mathrm{g} / \mathrm{ml}$. After treatment for $5 \mathrm{~min}$, three fish from each group were selected randomly, and two-fifths of each fish's body was cut, weighed, and homogenized in saline at a ratio of $100 \mathrm{mg} / \mathrm{ml}$ $(w / v)$. The lysates were spot-plated on LB agar dishes for bacterial survival assays. For quantification, each sample was spot-plated in triplicate. The injury and survival rates of the zebrafish were observed $48 \mathrm{~h}$ after antibiotics treatment. All experiments were performed three times. In addition, three fish scraped without infection were homogenized to count the basal number of bacteria in the fish themselves.

\section{RESULTS}

\section{Five-Minute Hypoionic Shock Treatment Enables Gentamicin and Neomycin to Kill Stationary-Phase Aquaculture Bacteria}

Bacteria in the stationary phase are highly tolerant to antibiotics under conventional treatment conditions, presumably due to stress- or starvation-induced growth arrest (Rittershaus et al., 2013; Martins et al., 2018). Here, we examined the antibiotic tolerance of six aquaculture bacteria, specifically Aeromonas hydrophila, Vibrio alginolyticus, Vibrio fluvialis, Vibrio harveyi, Edwardsiella tarda, and Streptococcus iniae (with the concentrations of these cells being $8.6 \times 10^{9}, 3 \times 10^{9}$, $3.6 \times 10^{9}, 3.9 \times 10^{9}, 5.5 \times 10^{8}$, and $3.4 \times 10^{8}$, respectively), by treating the stationary-phase cells with aminoglycoside antibiotics dissolved in $0.9 \% \mathrm{NaCl}$ solution (Figure $\mathbf{1}$ and Supplementary Figure S1). In China, gentamicin is widely used, and neomycin is the only aminoglycoside currently certified for aquaculture applications (Liu et al., 2017). Therefore, these two aminoglycosides were evaluated. We found that neither gentamicin nor neomycin could kill the above bacteria after incubation for 5 min when dissolved in $0.9 \% \mathrm{NaCl}$ solution. When the cells were treated with the antibiotics in $0.9 \% \mathrm{NaCl}$ solution for $3 \mathrm{~h}$, the bacteria exhibited different degrees of antibiotic susceptibility: 3.4 and $31.3 \%$ of A. hydrophila were killed by gentamicin and neomycin, respectively; $V$. alginolyticus, $V$. fluvialis, and $V$. harveyi were eliminated by $1 \sim 2$ orders of magnitude; E. tarda and S. iniae were killed by gentamycin by about 4 orders of magnitude.

Bacterial cells in the stationary phase were next treated with gentamicin- or neomycin-containing ultrapure water for $5 \mathrm{~min}$ for comparison with the antibiotic treatment in $0.9 \% \mathrm{NaCl}$ solution (Figure 2 and Supplementary Figure S2). Substantial amounts of all aquaculture bacteria were killed by neomycincontaining ultrapure water. Similarly, S. iniae colonies were undetectable on LB agar dishes after 5 min treatment with neomycin-containing ultrapure water (as indicated by the asterisks in Figure 2E), indicating a reduction in the surviving cells by more than 6 orders or magnitude. Notably, A. hydrophila, $V$. alginolyticus, E. tarda, and S. iniae were killed by gentamicincontaining ultrapure water by $3 \sim 4$ orders of magnitude, but only a very limited potentiation effect was observed on gentamicin with $V$. fluvialis and $V$. harveyi (Supplementary Figure S2B). In contrast, neither gentamicin nor neomycin had a killing effect when dissolved in the $\mathrm{NaCl}$ solution. These results indicate that 

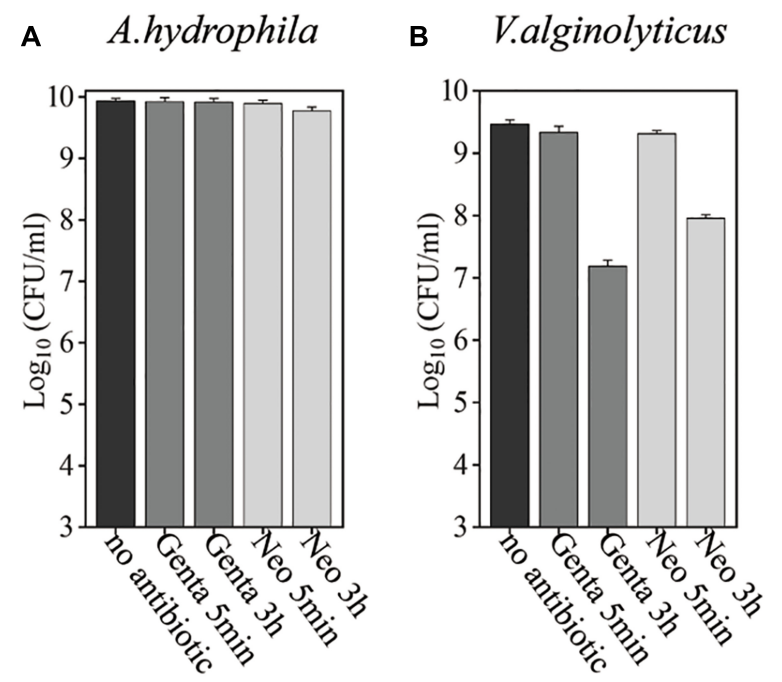

c V.fluvialis
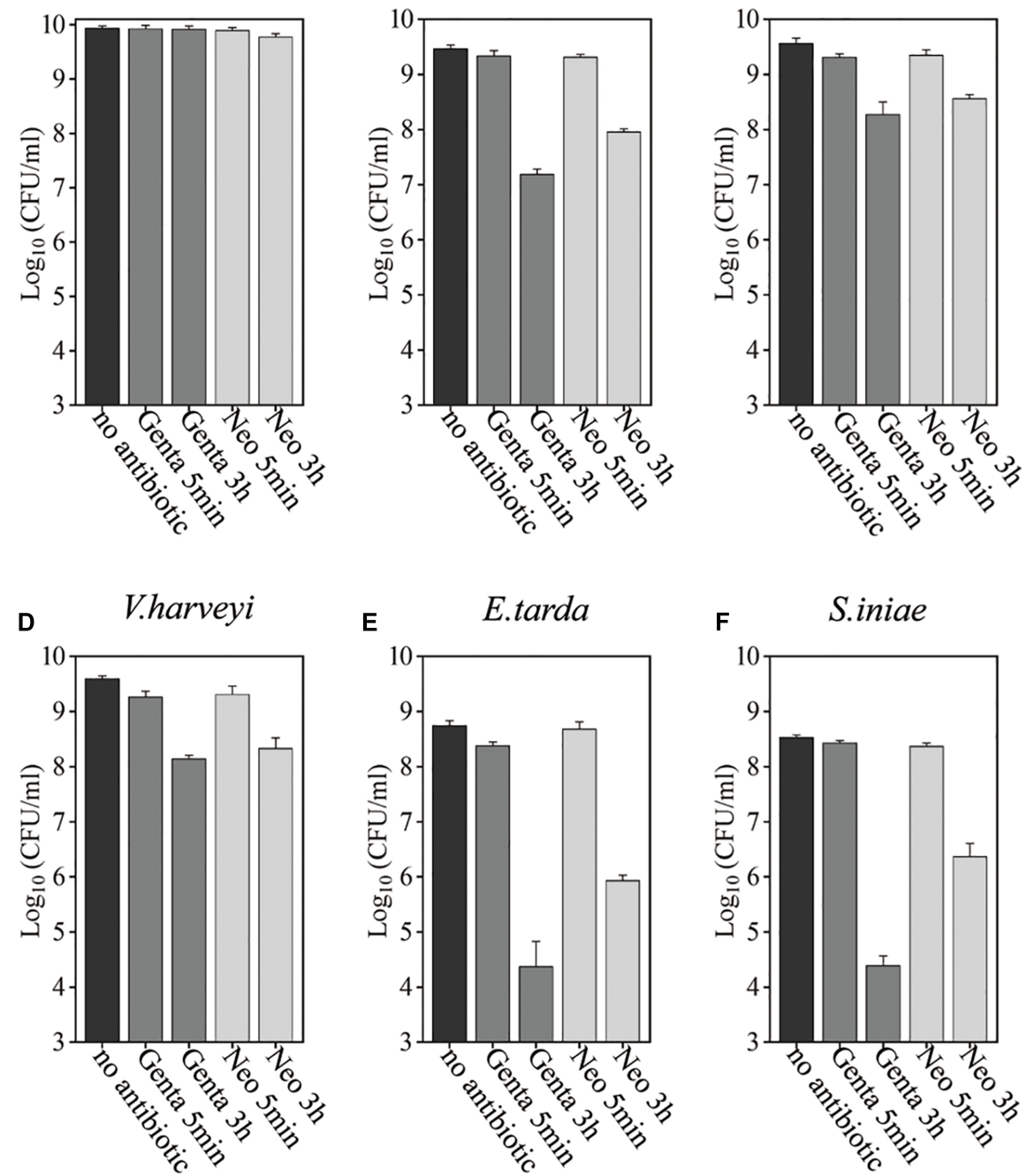

FIGURE 1 | Antibiotic tolerance of six aquaculture bacteria under conventional treatment conditions. (A-F) Stationary-phase cells of the indicated bacteria [Aeromonas hydrophila, Vibrio alginolyticus, Vibrio fluvialis, Vibrio harveyi, Edwardsiella tarda, and Streptococcus iniae, (A-F), respectively], which were treated with gentamicin (Genta) or neomycin (Neo) dissolved in $0.9 \% \mathrm{NaCl}$ solution for 5 min or $3 \mathrm{~h}$ and then spot-plated on Lysogeny broth (LB) agar dishes for cell survival assays. The concentrations of antibiotics used were as follows: $25 \mu \mathrm{g} / \mathrm{ml}$ of Genta and $50 \mu \mathrm{g} / \mathrm{ml} \mathrm{f} \mathrm{Neo} \mathrm{for} \mathrm{S}$. iniae; $100 \mu \mathrm{g} / \mathrm{ml} \mathrm{f} \mathrm{Genta}$ and $200 \mu \mathrm{g} / \mathrm{ml} \mathrm{f} \mathrm{Neo} \mathrm{for} \mathrm{the}$ other five bacteria.

hypoionic shock treatment enables aminoglycoside antibiotics to rapidly reduce stationary-phase aquaculture bacteria.

\section{Hypoionic Shock-Induced Gentamicin Potentiation Against Aquaculture Bacteria Is Partially Dependent on ATP}

The tolerance of bacteria to antibiotics is closely related to intracellular ATP levels (Meylan et al., 2017; Shan et al., 2017; Pu et al., 2019). We next sought to determine whether hypoionic shock-induced aminoglycoside potentiation against aquaculture bacteria is affected by the ATP level in the bacterial cells. CCCP and FCCP are uncouplers of the proton motive force (PMF) that drives ATP synthesis and thus are able to reduce intracellular
ATP levels (Kinoshita et al., 1984; Tapia et al., 2006). To this end, we treated aquaculture bacteria ( $A$. hydrophila, $V$. alginolyticus, E. tarda, and S. iniae) with CCCP and FCCP for $1 \mathrm{~h}$ and then subjected them to gentamicin treatment under hypoionic shock conditions (note: $V$. fluvialis and $V$. harveyi were not analyzed here due to a very limited potentiation effect of hypoionic shock on gentamicin).

Cell survival assays revealed that CCCP, as well as its functional analog FCCP, efficiently suppressed the hypoionic shock-induced gentamicin potentiation that kills stationary-phase aquaculture bacteria in $5 \mathrm{~min}$ (Figure 3 and Supplementary Figure S3). An intracellular ATP assay also confirmed that pretreatment with CCCP or FCCP significantly reduced the intracellular ATP levels in all of the bacteria 
A

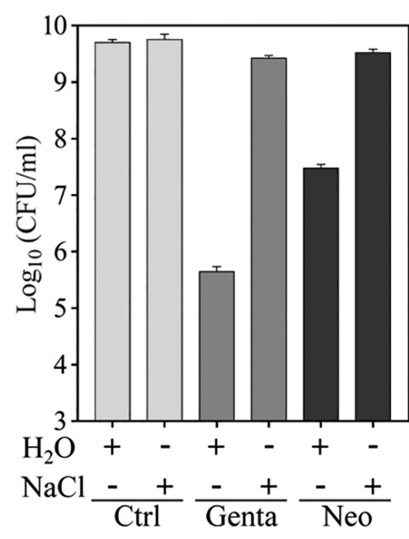

D

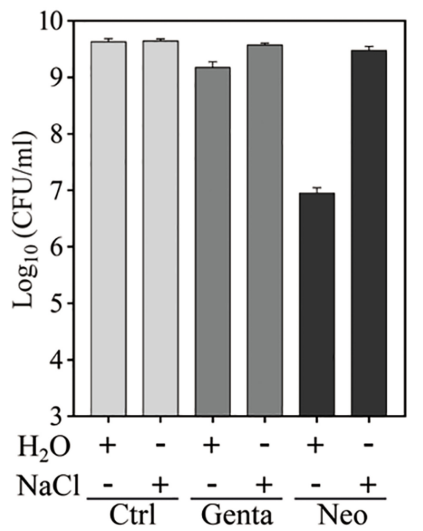

B

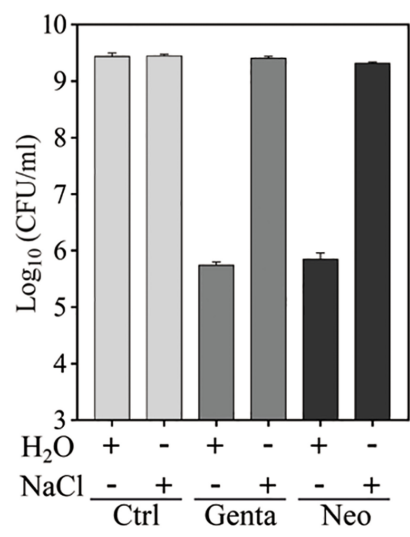

E

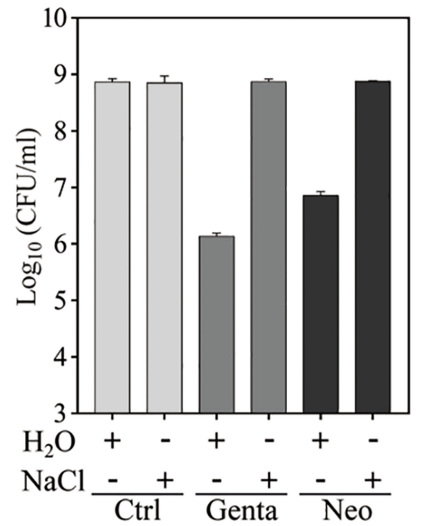

C

V.fluvialis

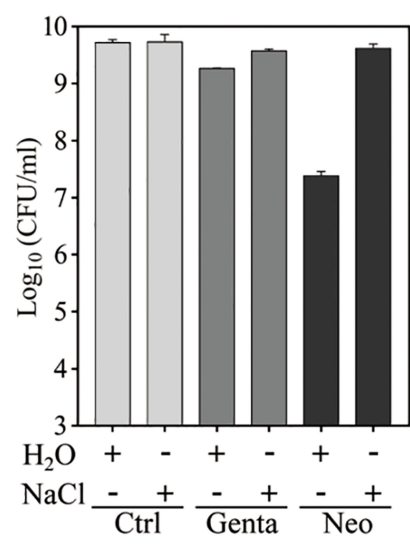

$\mathbf{F}$

S.iniae

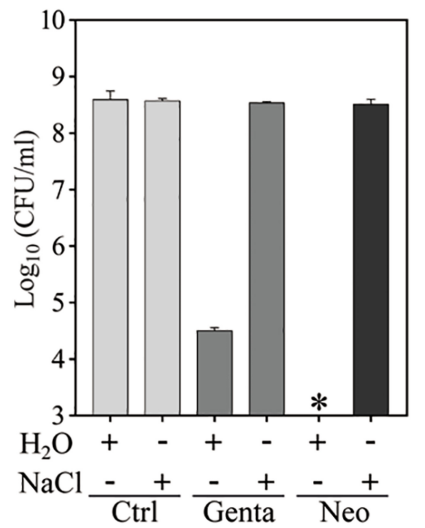

FIGURE 2 | Hypoionic shock-induced potentiation of gentamicin and neomycin effects against the six aquaculture bacteria. (A-F) Survival of stationary-phase cells of Aeromonas hydrophila (A) Vibrio alginolyticus (B), Vibrio fluvialis (C), Vibrio harveyi (D), Edwardsiella tarda (E), and Streptococcus iniae (F) following 5 min treatment with Genta or Neo dissolved in ultrapure water or $0.9 \% \mathrm{NaCl}$. The concentrations of antibiotics used were as follows: $25 \mu \mathrm{g} / \mathrm{ml}$ of $\mathrm{Genta}$ and $50 \mu \mathrm{g} / \mathrm{ml}$ of Neo for S. iniae; $100 \mu \mathrm{g} / \mathrm{ml}$ of Genta and $200 \mu \mathrm{g} / \mathrm{ml}$ of Neo for the other five bacteria. *in Panel F indicates that No CFU detected during cell survival assay by 100000-fold dilution.

evaluated (Figure 3). These results suggest that hypoionic shockinduced potentiation of gentamicin's effect against aquaculture bacteria is, at least, partially dependent on intracellular ATP.

\section{Hypoionic Shock Enhances the Bacterial Uptake of Gentamicin}

Aminoglycoside antibiotics such as gentamicin and tobramycin must traverse the bacterial cytoplasmic membrane prior to initiating their lethal effects, and the uptake of aminoglycosides is facilitated by the PMF or ATP (Taber et al., 1987; Fraimow et al., 1991; Allison et al., 2011). Therefore, we further explored whether hypoionic shock treatment affects the bacterial uptake of gentamicin antibiotics. For this purpose, fluorescent gentamicin was synthesized by conjugating coumarin-hemicyanine scaffolds to gentamicin (Wu et al., 2020). The conjugation did not affect the bactericidal efficacy of gentamicin (Supplementary Figure S4A). The fluorescent gentamicin taken up by $A$. hydrophila or $V$. alginolyticus was extracted through cell wall digestion coupled with cycled freezing/thawing and thermal denaturation and then subjected to a fluorescence assay. Fluorescent gentamicin at standard concentrations was directly incubated with bacterial lysates before a fluorescence assay. The maximal fluorescent intensity of fluorescent gentamicin was approximately $640 \mathrm{~nm}$ (Figure 4A).

A regression analysis (Supplementary Figure S4B) based on the standards (Figure 4A) showed that the concentration of gentamicin extracted from A. hydrophila upon hypoionic shock was approximately $69.58 \mu \mathrm{g} / \mathrm{ml}$, while that extracted from the cells treated with $0.9 \% \mathrm{NaCl}$ solution was only $37.96 \mu \mathrm{g} / \mathrm{ml}$. Notably, we found that the amount of gentamicin taken up by the cells pretreated with CCCP or FCCP was reduced to 60$70 \%$. Similarly, the concentration of gentamicin extracted from $V$. alginolyticus upon hypoionic shock was about $64.45 \mu \mathrm{g} / \mathrm{ml}$, which was significantly reduced in $\mathrm{NaCl}$ solution or upon pretreatment with CCCP or FCCP (Figure 4B). 
A A. hydrophila
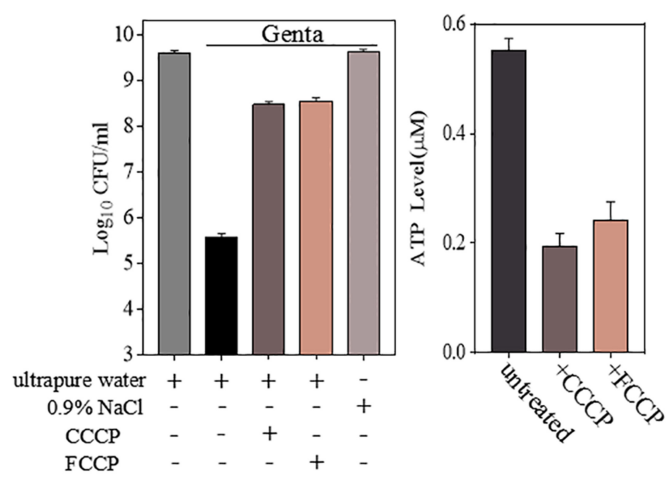

E.tarda

C

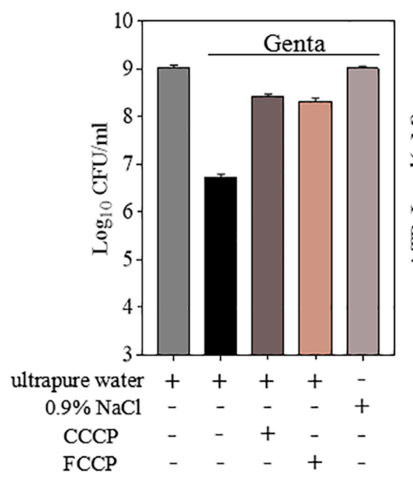

B

V.alginolyticus
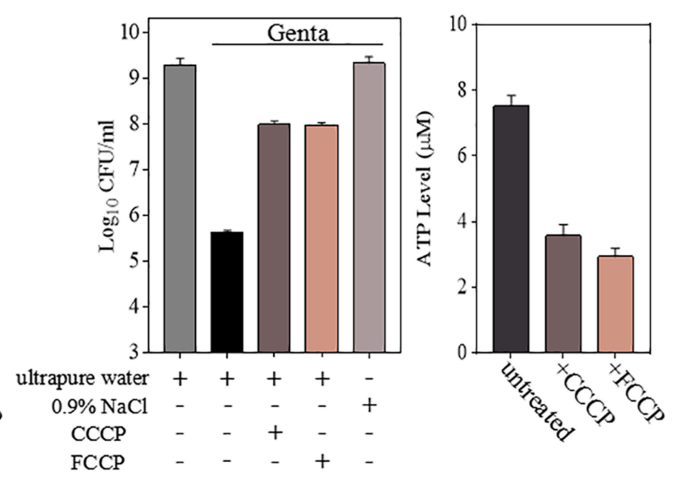

S.iniae

D

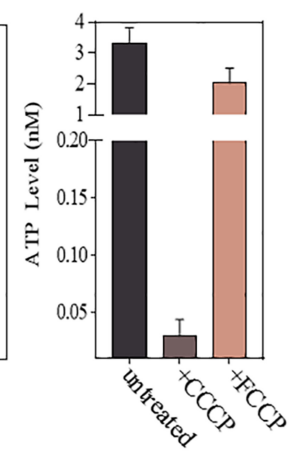

FIGURE 3 | Hypoionic shock-induced potentiation of gentamicin effects against aquatic pathogenic bacteria is partially dependent on ATP. (A-D) Left parts in each panel: survival of stationary-phase cells of Aeromonas hydrophila, Vibrio alginolyticus, Edwardsiella tarda, and Streptococcus iniae. Cells were pretreated with CCCP or FCCP for $1 \mathrm{~h}$ and then subjected to 5-min treatment with gentamicin dissolved in ultrapure water. Right parts in each panel: ATP levels in CCCP- or FCCP-pretreated cells.

\section{Gentamicin Under Hypoionic Shock Conditions Significantly Improved the Survival of Zebrafish Infected by Aeromonas hydrophila}

In recent years, zebrafish (Danio rerio) has been used as an important alternative to mammalian models in the study of human infectious disease (Allen and Neely, 2010; Meijer and Spaink, 2011; Sullivan et al., 2017). In order to explore the in vivo efficacy of combined treatment with hypoionic shock and also probe the potential application of the combined treatment against aquaculture bacterial pathogens, a zebrafish infection model was used in this study. After infection by A. hydrophila (for details, refer to the "Materials and Methods" section), the zebrafish were rinsed with deionized water for a few seconds and randomly divided into three groups before being subjected to different treatments for 5 min: mock treatment, gentamicin dissolved in ultrapure water $\left(\mathrm{Genta}+\mathrm{H}_{2} \mathrm{O}\right)$, and gentamicin dissolved in $\mathrm{NaCl}$ solution (Genta $+\mathrm{NaCl})$.

Bacterial cell survival assays revealed that $3.75 \times 10^{6} \mathrm{CFU} / \mathrm{ml}$ of A. hydrophila cells from the homogenate of wound tissues from zebrafish were viable without treatment (mock). Treatment with Genta $+\mathrm{NaCl}$ reduced the number of viable cells to
$3.3 \times 10^{5} \mathrm{CFU} / \mathrm{ml}$. Strikingly, viable A. hydrophila cells were almost undetectable when the zebrafish were treated with Genta $+\mathrm{H}_{2} \mathrm{O}$ (Figure 5A). These results indicated that shortterm exposure to gentamicin-containing ultrapure water is more effective at killing bacteria in infected fish than exposure to gentamicin-containing $\mathrm{NaCl}$ solution.

Consistently, we observed that the infection sites in some fish in the mock group and Genta $+\mathrm{NaCl}$ group became red and swollen $12 \mathrm{~h}$ after infection (Figure 5B). Animal survival assays revealed that approximately $20 \%$ of zebrafish in the control (mock) group began to die $12 \mathrm{~h}$ post-infection, and only about $60 \%$ of this group survived $48 \mathrm{~h}$ post-infection. In the Genta $+\mathrm{NaCl}$ group, $70 \%$ of zebrafish survived $48 \mathrm{~h}$ postinfection. Surprisingly, none of the zebrafish in the Genta $+\mathrm{H}_{2} \mathrm{O}$ group died or exhibited swelling (Figure 5C).

\section{DISCUSSION}

Outbreaks of infectious disease are considered a significant constraint in the aquaculture industry, causing more than 10 billion USD worth of losses annually on a global scale (Evensen, 2016). The currently available commercial vaccines are aimed at 

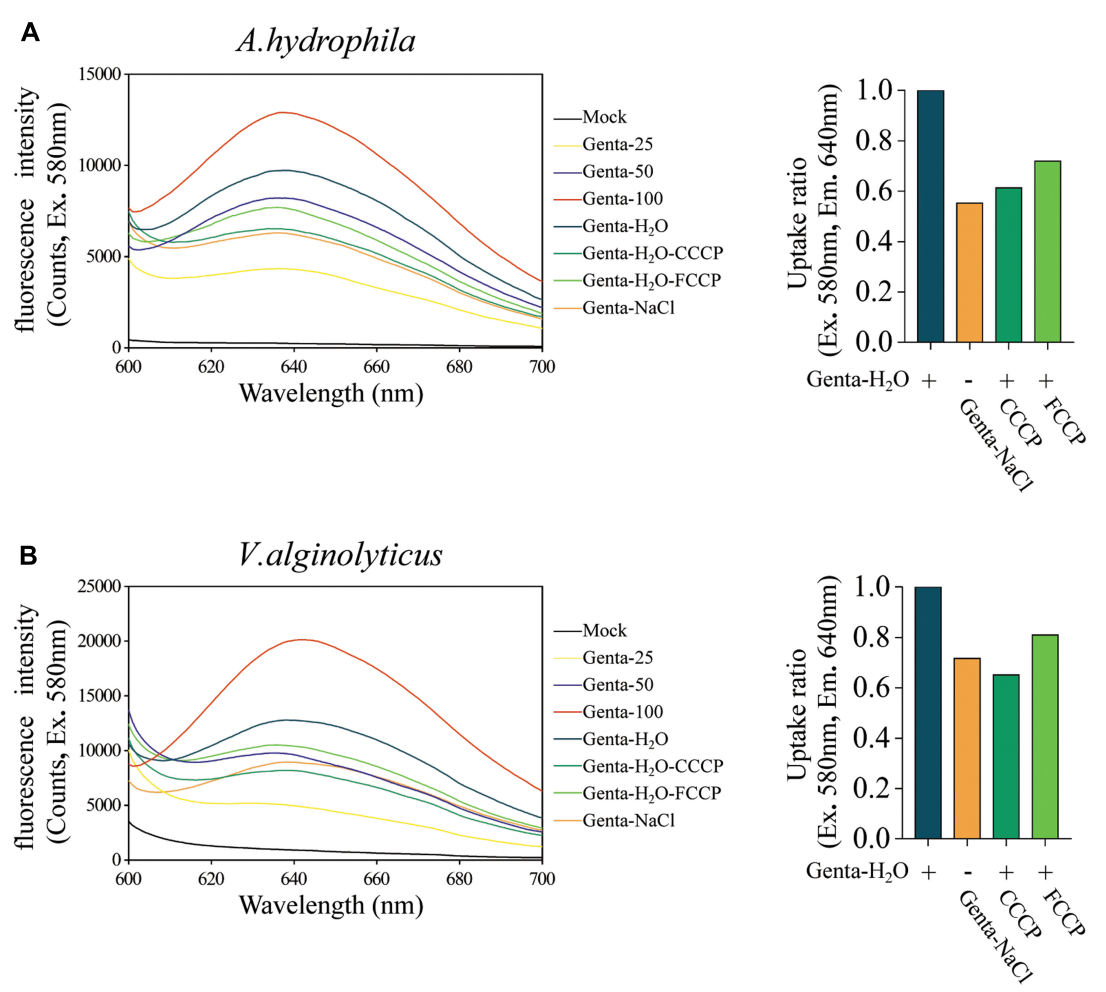

FIGURE 4 | Hypoionic shock enhances the bacterial uptake of fluorescent-labeled gentamicin. (A,B) Left parts: the fluorescence spectra for fluorescent gentamicin taken up by Aeromonas hydrophila (A) or Vibrio alginolyticus (B) were monitored with a spectrofluorometer. Mock, bacteria lysate without antibiotic treatment. Genta 25-100, standard concentration fluorescence labeled antibiotic (25, 50, and $100 \mu \mathrm{g} / \mathrm{ml})$ mixed with bacteria lysate. In the Genta- ${ }_{2} \mathrm{O}$ (Genta dissolved in ultrapure water), Genta- $\mathrm{NaCl}$ (Genta dissolved in saline), Genta- $\mathrm{H}_{2} \mathrm{O}-\mathrm{CCCP}$ (CCCP-pretreated and Genta dissolved in ultrapure water), and Genta- $\mathrm{H}_{2} \mathrm{O}-\mathrm{FCCP}$ (FCCP-pretreated and Genta dissolved in ultrapure water) groups, the fluorescent gentamicin taken up by bacterial cells was monitored with a spectrofluorometer. (A,B) Right parts: ratios for fluorescent gentamicin uptake in different experimental groups compared with those in the hypoionic shock-treated group (Genta- $\left.\mathrm{H}_{2} \mathrm{O}\right)$.

specific animals, for example, some fish and lobsters (Assefa and Abunna, 2018; Adams, 2019), and cannot be widely administered to other aquatic animals, especially invertebrates lacking acquired immunity. Most of the novel alternative biocontrol strategies for fish bacterial diseases, such as probiotics, bio-encapsulated vaccines, and phage therapy, are still in the research phase (PérezSánchez et al., 2018; Soliman et al., 2019). On the contrary, the activity spectrum, mode of action, resistance mechanisms, and current applications of most important antibiotic classes have been well investigated (Mohr, 2016). It is highly desirable to develop more effective and safer approaches for current antibiotics. For example, Peng et al. (2015) found that exogenous glucose or alanine plus kanamycin can kill multidrug-resistant Edwardsiella tarda both in vitro and in a mouse model for urinary tract infection. Glycerol monolaurate, lauric acid, 5methylindole, and even the commonly used diabetic drug metformin were found to act synergistically with aminoglycoside to eliminate Staphylococcus aureus persisters (Hess et al., 2014; Liu et al., 2020; Sun et al., 2020). Various adjuvants, including metabolites (Allison et al., 2011; Peng et al., 2015), for antibiotic potentiation have been well documented (Liu et al., 2019).

Here, we show that hypoionic shock enables gentamicin and/or neomycin antibiotics to reduce six stationary-phase aquaculture pathogenic bacteria, consistent with our previous studies (Jiafeng et al., 2015; Chen et al., 2019). Furthermore, this hypoionic shock-induced potentiation of gentamicin was also observed in zebrafish infected with Aeromonas hydrophila. Mechanistically, the potentiation seems to be achieved by enhancing the bacterial uptake of gentamicin under hypoionic shock conditions. Given pathogenic bacteria generally infect fish on the surface of the skin (Benhamed et al., 2014), our approach may represent a promising strategy for bacterial infection control in aquaculture. This approach is eco-friendly, non-toxic, and non-immunogenic, with the exception of the required operation to transfer the fish into aminoglycoside-containing ultrapure water. Currently, a small-scale application of this approach is being performed in our laboratory.

Our approach is also advantageous with respect to food safety and environmental health, given that it takes only a few minutes to complete the treatment; therefore, a smaller amount of antibiotics and less time for antibiotic exposure are required. As such, contamination of the environment by residual antibiotics and/or retention of the antibiotics within animal bodies can be minimized. Currently, the use of antibiotics in aquaculture leads to the accumulation of residual antibiotics in sea and freshwater foods (Song et al., 2017; Chen et al., 2018), which may have adverse effects on humans (Cabello, 2006). Similarly, residual antibiotics in water or aquatic sediments may facilitate the spread 

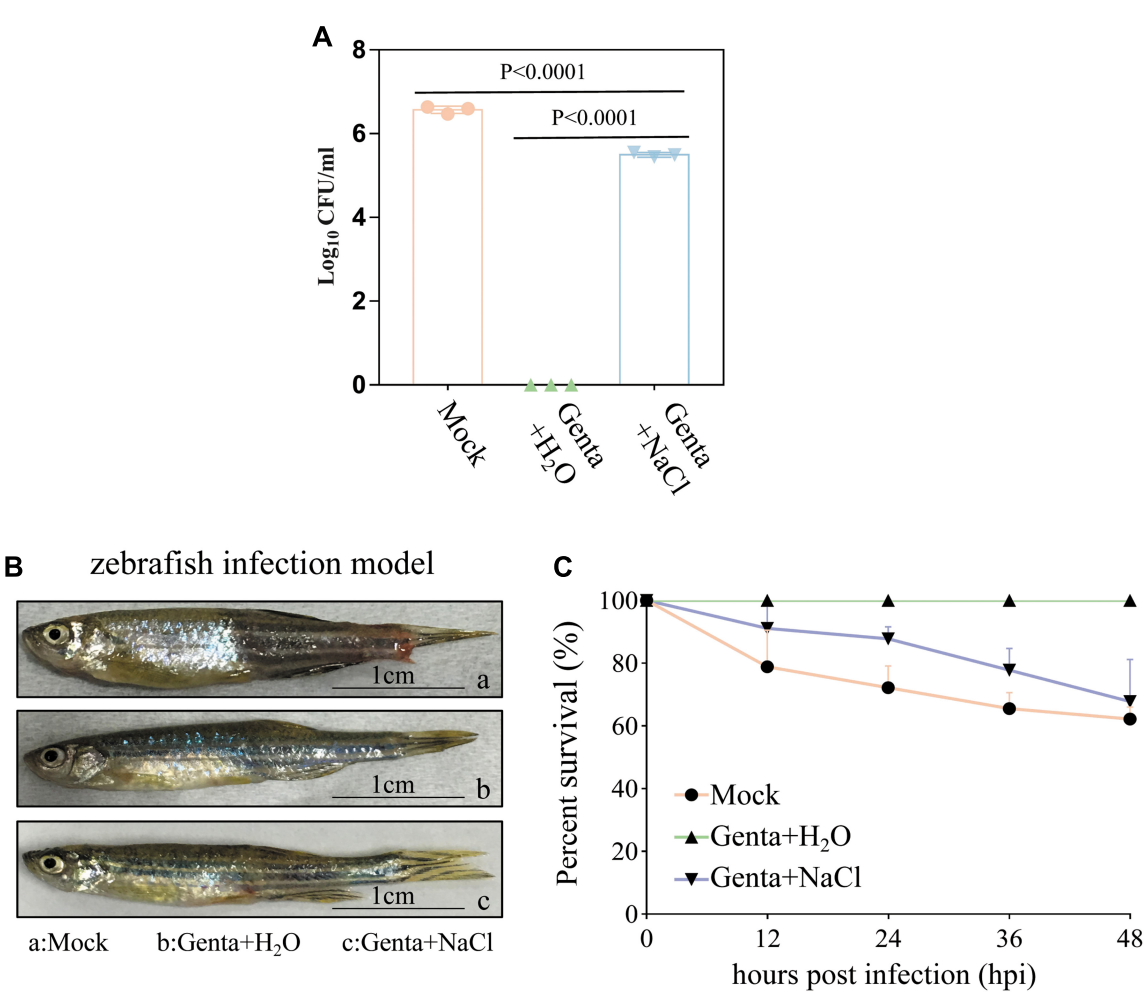

FIGURE 5 | Hypoionic shock facilitates gentamicin killing of Aeromonas hydrophila in a zebrafish model. (A) The survival percentage of the pathogenic bacteria on/in the zebrafish treated with gentamicin dissolved in ultrapure water (Genta $+\mathrm{H}_{2} \mathrm{O}$ ) or in $0.9 \% \mathrm{NaCl}$ solution (Genta $+\mathrm{NaCl}$ ) for only 5 min. The mock groups were not treated with antibiotics. The number of bacteria on/in the zebrafish before infection was subtracted (Supplementary Figure S5C) from the results for each group.

(B) The gross pathology of zebrafish infected by $A$. hydrophila at $12 \mathrm{~h}$. The infection site of some fish in the mock groups and salt treatment groups became red and swollen. (C) The survival percentage of zebrafish infected by A. hydrophila after $48 \mathrm{~h}$.

of antibiotic resistance in environmental bacteria (Gullberg et al., 2011; Cabello et al., 2016). In addition, compared with the stimulation of aminoglycoside potentiation by metabolites, which takes a few hours to manifest (Allison et al., 2011; Peng et al., 2015), our approach, which does not consume metabolites and requires only a few minutes, may have certain advantages.

\section{DATA AVAILABILITY STATEMENT}

The original contributions presented in the study are included in the article/Supplementary Material, further inquiries can be directed to the corresponding author/s.

\section{ETHICS STATEMENT}

The animal study was reviewed and approved by the Animal Ethical and Welfare Committee of Fujian Normal University (approval no. IACUC 20190006, Fuzhou, China).

\section{AUTHOR CONTRIBUTIONS}

$\mathrm{XF}$ and YG designed the study. ZC and WY performed the experiments. DL synthesized the fluorescent gentamicin. YG and
XF analyzed the data and wrote the manuscript. All authors contributed to the article and approved the submitted version.

\section{FUNDING}

This work was supported by the research grants from the National Natural Science Foundation of China (Nos. 31972918 and 31770830 to XF) and Natural Science Foundation of Fujian Province (No. 2020J01175 to YG).

\section{ACKNOWLEDGMENTS}

We thank Prof. Yueling Zhang at Shantou University and Dr. Chao Wang at Shandong Freshwater Fisheries Research Institute for their kindness in providing bacterial strains as described in Supplementary Table S1.

\section{SUPPLEMENTARY MATERIAL}

The Supplementary Material for this article can be found online at: https://www.frontiersin.org/articles/10.3389/fmicb.2021. 641846/full\#supplementary-material 


\section{REFERENCES}

Adams, A. (2019). Progress, challenges and opportunities in fish vaccine development. Fish Shellfish Immunol. 90, 210-214. doi: 10.1016/j.fsi.2019.04. 066

Allen, J. P., and Neely, M. N. (2010). Trolling for the ideal model host: zebrafish take the bait. Future Microbiol. 5, 563-569. doi: 10.2217/fmb.10.24

Allison, K. R., Brynildsen, M. P., and Collins, J. J. (2011). Metabolite-enabled eradication of bacterial persisters by aminoglycosides. Nature 473, 216-220. doi: 10.1038/nature10069

Assefa, A., and Abunna, F. (2018). Maintenance of fish health in aquaculture: review of epidemiological approaches for prevention and control of infectious disease of fish. Vet. Med. Int. 2018:5432497. doi: 10.1155/2018/5432497

Baym, M., Stone, L. K., and Kishony, R. (2016). Multidrug evolutionary strategies to reverse antibiotic resistance. Science (New York, N.Y.) 351:aad3292. doi: 10.1126/science.aad3292

Benhamed, S., Guardiola, F. A., Mars, M., and Esteban, M. (2014). Pathogen bacteria adhesion to skin mucus of fishes. Vet. Microbiol. 171, 1-12. doi: 10. 1016/j.vetmic.2014.03.008

Cabello, F. C. (2006). Heavy use of prophylactic antibiotics in aquaculture: a growing problem for human and animal health and for the environment. Environ. Microbiol. 8, 1137-1144. doi: 10.1111/j.1462-2920.2006.01054.x

Cabello, F. C., Godfrey, H. P., Buschmann, A. H., and Dölz, H. J. (2016). Aquaculture as yet another environmental gateway to the development and globalisation of antimicrobial resistance. Lancet Infect. Dis. 16, e127-e133. doi: 10.1016/s1473-3099(16)00100-6

Chen, H., Liu, S., Xu, X. R., Diao, Z. H., Sun, K. F., Hao, Q. W., et al. (2018). Tissue distribution, bioaccumulation characteristics and health risk of antibiotics in cultured fish from a typical aquaculture area. J. Hazard. Mater. 343, 140-148. doi: 10.1016/j.jhazmat.2017.09.017

Chen, Z., Gao, Y., Lv, B., Sun, F., Yao, W., Wang, Y., et al. (2019). Hypoionic shock facilitates aminoglycoside killing of both nutrient shift- and starvationinduced bacterial persister cells by rapidly enhancing aminoglycoside uptake. Front. Microbiol. 10:2028. doi: 10.3389/fmicb.2019.02028

Dhar, A. K., Manna, S. K., and Thomas Allnutt, F. C. (2014). Viral vaccines for farmed finfish. Virusdisease 25, 1-17. doi: 10.1007/s13337-013-0186-4

Du, B., Yang, Q., Wang, R., Wang, R., Wang, Q., and Xin, Y. (2019). Evolution of antibiotic resistance and the relationship between the antibiotic resistance genes and microbial compositions under long-term exposure to tetracycline and sulfamethoxazole. Int. J. Environ. Res. Public Health 16:4681. doi: 10.3390/ ijerph16234681

Evensen, $\varnothing$ (2016). "Development of fish vaccines: focusing on methods," in Fish Vaccines, Birkhäuser Advances in Infectious Diseases, ed. A. Adams (Basel: Springer Basel), 53-74. doi: 10.1007/978-3-0348-0980-1_3

Fraimow, H. S., Greenman, J. B., Leviton, I. M., Dougherty, T. J., and Miller, M. H. (1991). Tobramycin uptake in Escherichia coli is driven by either electrical potential or ATP. J. Bacteriol. 173, 2800-2808. doi: 10.1128/jb.173.9.2800-2808. 1991

Froehlich, H. E., Runge, C. A., Gentry, R. R., Gaines, S. D., and Halpern, B. S. (2018). Comparative terrestrial feed and land use of an aquaculturedominant world. Proc. Natl. Acad. Sci. U.S.A. 115, 5295-5300. doi: 10.1073/ pnas. 1801692115

Gullberg, E., Cao, S., Berg, O. G., Ilbäck, C., Sandegren, L., Hughes, D., et al. (2011). Selection of resistant bacteria at very low antibiotic concentrations. PLoS Pathog. 7:e1002158. doi: 10.1371/journal.ppat.1002158

Haenen, O. L., Evans, J. J., and Berthe, F. (2013). Bacterial infections from aquatic species: potential for and prevention of contact zoonoses. Rev. Sci. Tech. 32, 497-507. doi: 10.20506/rst.32.2.2245

Hess, D. J., Henry-Stanley, M. J., and Wells, C. L. (2014). Antibacterial synergy of glycerol monolaurate and aminoglycosides in Staphylococcus aureus biofilms. Antimicrob. Agents Chemother. 58, 6970-6973. doi: 10.1128/aac.03672-14

Jiafeng, L., Fu, X., and Chang, Z. (2015). Hypoionic shock treatment enables aminoglycosides antibiotics to eradicate bacterial persisters. Sci. Rep. 5:14247. doi: $10.1038 /$ srep 14247

Kinoshita, N., Unemoto, T., and Kobayashi, H. (1984). Proton motive force is not obligatory for growth of Escherichia coli. J. Bacteriol. 160, 1074-1077. doi: 10.1128/jb.160.3.1074-1077.1984
Kotob, M. H., Menanteau-Ledouble, S., Kumar, G., Abdelzaher, M., and ElMatbouli, M. (2017). Erratum to: the impact of co-infections on fish: a review. Vet. Res. 48:26. doi: 10.1186/s13567-017-0432-7

Lafferty, K. D., Harvell, C. D., Conrad, J. M., Friedman, C. S., Kent, M. L., Kuris, A. M., et al. (2015). Infectious diseases affect marine fisheries and aquaculture economics. Annu. Rev. Mar. Sci. 7, 471-496. doi: 10.1146/annurev-marine010814-015646

Levin, B. R., and Rozen, D. E. (2006). Non-inherited antibiotic resistance. Nat. Rev. Microbiol. 4, 556-562. doi: 10.1038/nrmicro1445

Levy, S. B., and Marshall, B. (2004). Antibacterial resistance worldwide: causes, challenges and responses. Nat. Med. 10, S122-S129. doi: 10.1038/nm1145

Little, D. C., Newton, R. W., and Beveridge, M. C. (2016). Aquaculture: a rapidly growing and significant source of sustainable food? Status, transitions and potential. Proc. Nutr. Soc. 75, 274-286. doi: 10.1017/s0029665116000665

Liu, X., Steele, J. C., and Meng, X. Z. (2017). Usage, residue, and human health risk of antibiotics in Chinese aquaculture: a review. Environ. Pollut. (Barking, Essex 1987) 223, 161-169. doi: 10.1016/j.envpol.2017.01.003

Liu, Y., Jia, Y., Yang, K., Li, R., Xiao, X., Zhu, K., et al. (2020). Metformin restores tetracyclines susceptibility against multidrug resistant bacteria. $A d v$. Sci. (Weinheim Baden Wurttemberg Germany) 7:1902227. doi: 10.1002/advs. 201902227

Liu, Y., Li, R., Xiao, X., and Wang, Z. (2019). Antibiotic adjuvants: an alternative approach to overcome multi-drug resistant Gram-negative bacteria. Crit. Rev. Microbiol. 45, 301-314. doi: 10.1080/1040841X.2019.1599813

Martins, D., Mckay, G., Sampathkumar, G., Khakimova, M., and Nguyen, D. (2018). Superoxide dismutase activity confers (p)ppGpp-mediated antibiotic tolerance to stationary-phase Pseudomonas aeruginosa. Proc. Natl. Acad. Sci. U.S.A. 115:201804525. doi: 10.1073/pnas.1804525115

Matsuura, Y., Terashima, S., Takano, T., and Matsuyama, T. (2019). Current status of fish vaccines in Japan. Fish Shellfish Immunol. 95, 236-247. doi: 10.1016/j.fsi. 2019.09.031

McCall, I. C., Shah, N., Govindan, A., Baquero, F., and Levin, B. R. (2019). Antibiotic killing of diversely generated populations of nonreplicating bacteria. Antimicrob. Agents Chemother. 63:e02360-18. doi: 10.1128/AAC.02360-18

Meijer, A. H., and Spaink, H. P. (2011). Host-pathogen interactions made transparent with the zebrafish model. Curr. Drug Targets 12, 1000-1017. doi: 10.2174/138945011795677809

Meylan, S., Porter, C. B. M., Yang, J. H., Belenky, P., Gutierrez, A., Lobritz, M. A., et al. (2017). Carbon sources tune antibiotic susceptibility in Pseudomonas aeruginosa via tricarboxylic acid cycle control. Cell Chem. Biol. 24, 195-206. doi: 10.1016/j.chembiol.2016.12.015

Mohr, K. I. (2016). History of antibiotics research. Curr. Top. Microbiol. Immunol. 398, 237-272. doi: 10.1007/82_2016_499

Nambiar, S., Laessig, K., Toerner, J., Farley, J., and Cox, E. (2014). Antibacterial drug development: challenges, recent developments, and future considerations. Clin. Pharmacol. Ther. 96, 147-149. doi: 10.1038/clpt.2014.116

Navarro Llorens, J. M., Tormo, A., and Martínez-García, E. (2010). Stationary phase in gram-negative bacteria. FEMS Microbiol. Rev. 34, 476-495. doi: 10 . 1111/j.1574-6976.2010.00213.x

Neely, M. N., Pfeifer, J. D., and Caparon, M. (2002). Streptococcus-zebrafish model of bacterial pathogenesis. Infect. Immun. 70, 3904-3914. doi: 10.1128/iai.70.7. 3904-3914.2002

Peng, B., Su, Y. B., Li, H., Han, Y., Guo, C., Tian, Y. M., et al. (2015). Exogenous alanine and/or glucose plus kanamycin kills antibiotic-resistant bacteria. Cell Metab. 21, 249-262. doi: 10.1016/j.cmet.2015.01.008

Pérez-Sánchez, T., Mora-Sánchez, B., and Balcázar, J. L. (2018). Biological approaches for disease control in aquaculture: advantages, limitations and challenges. Trends Microbiol. 26, 896-903. doi: 10.1016/j.tim.2018.05.002

Pu, Y., Li, Y., Jin, X., Tian, T., Ma, Q., Zhao, Z., et al. (2019). ATP-dependent dynamic protein aggregation regulates bacterial dormancy depth critical for antibiotic tolerance. Mol. Cell 73, 143-156.e144. doi: 10.1016/j.molcel.2018.10. 022

Rittershaus, E. S., Baek, S. H., and Sassetti, C. M. (2013). The normalcy of dormancy: common themes in microbial quiescence. Cell Host Microbe 13, 643-651. doi: 10.1016/j.chom.2013.05.012

Sánchez-Vázquez, F. J., Terry, M. I., Felizardo, V. O., and Vera, L. M. (2011). Daily rhythms of toxicity and effectiveness of anesthetics (MS222 and eugenol) in 
zebrafish (Danio rerio). Chronobiol. Int. 28, 109-117. doi: 10.3109/07420528. 2010.538105

Santos, L., and Ramos, F. (2018). Antimicrobial resistance in aquaculture: current knowledge and alternatives to tackle the problem. Int. J. Antimicrob. Agents 52, 135-143. doi: 10.1016/j.ijantimicag.2018.03.010

Shan, Y., Brown Gandt, A., Rowe, S. E., Deisinger, J. P., Conlon, B. P., and Lewis, K. (2017). ATP-dependent persister formation in Escherichia coli. mBio 8:e02267-16. doi: 10.1128/mBio.02267-16

Soliman, W. S., Shaapan, R. M., Mohamed, L. A., and Gayed, S. S. R. (2019). Recent biocontrol measures for fish bacterial diseases, in particular to probiotics, bioencapsulated vaccines, and phage therapy. Open Vet. J. 9, 190-195. doi: 10.4314/ ovj.v9i3.2

Song, C., Li, L., Zhang, C., Qiu, L., Fan, L., Wu, W., et al. (2017). Dietary risk ranking for residual antibiotics in cultured aquatic products around Tai Lake, China. Ecotoxicol. Environ. Saf. 144, 252-257. doi: 10.1016/j.ecoenv.2017.06. 036

Sullivan, C., Matty, M. A., Jurczyszak, D., Gabor, K. A., Millard, P. J., Tobin, D. M., et al. (2017). Infectious disease models in zebrafish. Methods Cell Biol. 138, 101-136. doi: 10.1016/bs.mcb.2016.10.005

Sun, F., Bian, M., Li, Z., Lv, B., Gao, Y., Wang, Y., et al. (2020). 5Methylindole potentiates aminoglycoside against gram-positive bacteria including Staphylococcus aureus persisters under hypoionic conditions. Front. Cell. Infect. Microbiol. 10:84. doi: 10.3389/fcimb.2020.00084

Taber, H. W., Mueller, J. P., Miller, P. F., and Arrow, A. S. (1987). Bacterial uptake of aminoglycoside antibiotics. Microbiol. Rev. 51, 439-457. doi: 10.1128/MMBR. 51.4.439-457.1987

Tafalla, C., Bøgwald, J., and Dalmo, R. A. (2013). Adjuvants and immunostimulants in fish vaccines: current knowledge and future perspectives. Fish Shellfish Immunol. 35, 1740-1750. doi: 10.1016/j.fsi.2013.02.029

Takano, T., Matsuyama, T., Sakai, T., Nakamura, Y., Kamaishi, T., Nakayasu, C., et al. (2016). Ichthyobacterium seriolicida gen. nov., sp. nov., a member of the phylum 'Bacteroidetes', isolated from yellowtail fish (Seriola quinqueradiata) affected by bacterial haemolytic jaundice, and proposal of a new family, Ichthyobacteriaceae fam. nov. Int. J. Syst. Evol. Microbiol. 66, 580-586. doi: 10.1099/ijsem.0.000757

Tapia, J. A., Jensen, R. T., and García-Marín, L. J. (2006). Rottlerin inhibits stimulated enzymatic secretion and several intracellular signaling transduction pathways in pancreatic acinar cells by a non-PKC-delta-dependent mechanism. Biochim. Biophys. Acta. 1763, 25-38. doi: 10.1016/j.bbamcr.2005. 10.007

Wu, L., Chen, L., Kou, M., Dong, Y., Deng, W., Ge, L., et al. (2020). The ratiometric fluorescent probes for monitoring the reactive inorganic sulfur species (RISS) signal in the living cell. Spectrochim. Acta A Mol. Biomol. Spectrosc. 231:118141. doi: 10.1016/j.saa.2020.118141

Yao, Z., Wang, Z., Sun, L., Li, W., Shi, Y., Lin, L., et al. (2016). Quantitative proteomic analysis of cell envelope preparations under iron starvation stress in Aeromonas hydrophila. BMC Microbiol. 16:161. doi: 10.1186/s12866-0160769-5

Zhang, Q., Dong, X., Chen, B., Zhang, Y., Zu, Y., and Li, W. (2016). Zebrafish as a useful model for zoonotic Vibrio parahaemolyticus pathogenicity in fish and human. Dev. Comp. Immunol. 55, 159-168. doi: 10.1016/j.dci.2015.10.021

Conflict of Interest: The authors declare that the research was conducted in the absence of any commercial or financial relationships that could be construed as a potential conflict of interest.

Copyright (c) 2021 Gao, Chen, Yao, Li and Fu. This is an open-access article distributed under the terms of the Creative Commons Attribution License (CC BY). The use, distribution or reproduction in other forums is permitted, provided the original author(s) and the copyright owner(s) are credited and that the original publication in this journal is cited, in accordance with accepted academic practice. No use, distribution or reproduction is permitted which does not comply with these terms. 